\title{
Learned predation risk management by spider mites
}

\section{Thomas Hackl and Peter Schausberger*}

Group of Arthropod Ecology and Behavior, Division of Plant Protection, Department of Crop Sciences, University of Natural Resources and Life Sciences, Vienna, Austria

Edited by:

Martin Stevens, University of

Exeter, UK

\section{Reviewed by:}

Carita Lindstedt, University of Jyväskylä, Finland

Keiko Oku, NARO Agricultural

Research Center, Japan

\section{*Correspondence:}

Peter Schausberger, Group of Arthropod Ecology and Behavior, Division of Plant Protection,

Department of Crop Sciences, University of Natural Resources and

Life Sciences, Vienna, Peter

Jordanstrasse 82, 1190 Vienna,

Austria

e-mail: peter.schausberger@boku. ac.at
Predation is a prime selective force shaping prey behavior. Investment in anti-predator behavior is traded-off against time and energy for other fitness-enhancing activities such as foraging or reproduction. To optimize this benefit/cost trade-off, prey should be able to innately and/or by experience modulate their behavior to the level of predation risk. Here, we assessed learned predation risk management in the herbivorous two-spotted spider mite Tetranychus urticae. We exposed spider mites coming from benign (naïve) or high immediate predation risk (experienced) environments to latent and/or no risk and assessed their site choice, activity and oviposition. Benign environments were characterized by the absence of any predator cues, high immediate risk environments by killed spider mites, physical presence of the predatory mite Phytoseiulus persimilis and associated chemosensory traces left on the surface, and latent risk environments by only predator traces. In the no-choice experiment both naïve and experienced spider mites laid their first egg later on leaves with than without predator traces. Irrespective of predator traces presence/absence, experienced mites laid their first egg earlier than naïve ones did. Naïve spider mites were more active, indicating higher restlessness, and laid fewer eggs on leaves with predator traces, whereas experienced mites were less active and laid similar numbers of eggs on leaves with and without predator traces. In the choice experiment both naïve and experienced spider mites preferentially resided and oviposited on leaves without predator traces but experienced mites were less active than naïve ones. Overall, our study suggests that spider mites experienced with high predation risk behave bolder under latent risk than naïve spider mites. Since predator traces alone do not indicate immediate risk, we argue that the attenuated anti-predator response of experienced spider mites represents adaptive learned risk management.

Keywords: anti-predator behavior, learning, predatory mites, risk management, spider mites, threat-sensitivity

\section{INTRODUCTION}

Predation leads, by definition, to the killing of prey. However, predator-prey interactions result relatively rarely in prey's death because prey commonly change their behavior in presence of predators or when perceiving indirect or direct cues indicating predation risk. Common anti-predator strategies include avoidance, escape, taking refuge, shifting activities, or increasing aggregation (Lima and Dill, 1990; Kats and Dill, 1998). Antipredator behaviors evolve for the benefit of decreasing prey's risk of predation but entail costs paid in less time and energy available for other fitness-enhancing activities such as foraging or reproduction (Lima, 1998). To optimize the trade-off between the benefits and costs of anti-predator strategies, prey should evolve abilities to accurately recognize and grade predation risk. The hypothesis of fine-tuned behavioral flexibility of prey in response to different levels of predation risk is termed threatsensitive predator avoidance hypothesis and has been originally developed by Sih (1982) and Helfman (1989). The predictions of this hypothesis have been experimentally assessed and shown across diverse animal taxa, both vertebrates and invertebrates, and habitats, both aquatic (e.g., Kelley and Magurran, 2003; Turner et al., 2006; de Oliveira Mesquita and Young, 2007) and terrestrial (e.g., Maloney and McLean, 1995; Murray et al., 2004; Walzer and Schausberger, 2011).

Anti-predator behaviors and threat sensitivity, respectively, may be innate (e.g., Gallie et al., 2001), learned (e.g., Chivers and Smith, 1998; Ferrari and Chivers, 2006), or a combination of both (e.g., Mathis et al., 1996; Walzer and Schausberger, 2011). Furthermore, threat sensitivity may be interspecific, i.e., prey distinguish between predator species varying in risk (Walzer and Schausberger, 2011), or intraspecific, i.e., prey distinguish between different risk levels within one and the same predator species, such as cue concentration, density, ontogenetic stage, size, etc. (e.g., Ferrari et al., 2006). Here, we assessed learned intraspecific predation risk management in the two-spotted spider mite Tetranychus urticae. T. urticae is a globally distributed, highly polyphagous herbivore occurring on more than 1000 different host plant species (Bolland et al., 1998). T. urticae is known to possess innate inter- (Grostal and Dicke, 2000; Fernández-Ferrari and Schausberger, 2013) and intra-specific (Skaloudová et al., 2007) threat-sensitive predator recognition abilities. Typical anti-predator responses of adult spider mite females are increased activity, indicating higher restlessness and escaping attempts, and delayed and/or decreased oviposition. 
Overall, these behaviors should decrease both own and offspring predation risk but entail inherent time and energetic costs and trade-offs with other fitness-relevant life activities, respectively. For example, Grostal and Dicke (2000) investigated the response of T. urticae to chemical cues from enemy and non-enemy mite species. The spider mites foraged and oviposited less on leaves that were previously exposed to predatory mites than on clean leaves and leaves harboring cues of harmless fungivorous and pollen-feeding mites. Fernández-Ferrari and Schausberger (2013) showed that T. urticae females can innately discriminate between high (prey specialists) and low risk (diet generalists) predatory mite species and adjust their activities and oviposition behaviors accordingly. Skaloudová et al. (2007) observed shifts in oviposition behavior of T. urticae when exposed to various cues of a high risk predator. They placed adult spider mite females on leaves with graded risk levels (no predator cues, direct chemosensory predator cues on the surface or visual cues of a caged predator) and detected that increasing risk correlated with decreasing oviposition.

While innate threat-sensitive anti-predator behavior of T. urticae is well documented, a possible learning component has never been looked at. Thus, our primary aim was investigating whether experience modulates the anti-predator behavior of T. urticae in response to chemosensory cues of their prime natural enemies, plant-inhabiting predatory mites such as Phytoseiulus persimilis. Our study was based on the knowledge gained in previous studies (Fernández-Ferrari and Schausberger, 2013) that the spider mites are inter-specifically threat-sensitive and, among different predatory mite species, respond the strongest to the high risk predator $P$. persimilis. We conducted no-choice and choice experiments to compare the behavior (activity, site preference and oviposition) of predator-naïve and -experienced spider mites when exposed to chemosensory predator cues, i.e., traces such as metabolic waste products and footprints left by $P$. persimilis, on leaves. To assess learned intraspecific predation risk management we moved the spider mites from high immediate risk (thus predator-experienced) and no risk (thus predator-naïve) to latent risk environments. High immediate risk was characterized by physical predator presence, killed conspecifics, and chemosensory traces left by the predators on the surface, latent risk was characterized by only chemosensory predator traces, and no risk by the absence of any predator cues. We expected that the spider mites should optimally balance past and current activities, especially reproductive efforts, and adjust them to past and current predation risk. Accordingly, predator-naïve spider mites coming from benign environments should more strongly respond to latent predation risk than predator-experienced spider mites coming from high immediate predation risk environments.

\section{MATERIALS AND METHODS GENERATING PREDATOR-NAÏVE AND -EXPERIENCED SPIDER MITE FEMALES}

In both experiments, no-choice and choice, we tested predatornaïve and -experienced spider mite females. Naïve spider mites did not have any contact with the predatory mite $P$. persimilis and their cues, while experienced spider mites were exposed to $P$. persimilis and their cues for $48 \mathrm{~h}$ before the experiment. To generate predator-naïve and -experienced spider mites, randomly selected adult $T$. urticae females were transferred from the stock population onto bean leaf arenas of similar size $(10 \times 7 \mathrm{~cm} ; 15$ spider mites per arena), delimited by moist tissue paper. Leaf arenas consisted of detached common bean leaves, Phaseolus vulgaris, placed upside down on water-saturated foam cubes. About $12 \mathrm{~h}$ later, two gravid $P$. persimilis females each were placed on every second arena for $48 \mathrm{~h}$ (to generate experienced spider mites), while the other arenas were left without predators (to generate naïve spider mites). After removing the predatory mites and their eggs the arenas were left undisturbed for an additional $12 \mathrm{~h}$ before being used in the experiment. The ratio between spider mite females and predators was chosen such to ensure encounter between the spider mite females and the predatory mites but at the same time prevent artificial selection, i.e., to avoid that only those individuals remained for the experiment that had a genetically determined superior ability to survive attacks by the predatory mites. The predatory mites have a preference for the egg stage and rarely attack and kill adult females (Blackwood et al., 2001). All leaf arenas were kept in environmental chambers at 25 $\pm 1{ }^{\circ} \mathrm{C}, 60 \pm 5 \% \mathrm{RH}$, and 16:8 h L:D.

\section{GENERATING LEAF DISCS WITH AND WITHOUT PREDATOR CUES}

In both experiments, we used leaf discs with and without predatory mite cues. Cues were traces such a metabolic waste products and/or footprints left by the predators on the leaf surface. Circular leaf discs (ø $13 \mathrm{~mm}$ ) were punched from a clean trifoliate bean leaf and placed on top of a water column inside cylindrical compartments $(\varnothing 15 \mathrm{~mm})$ of a plastic cartridge. To create leaf discs with predatory mite cues one gravid adult $P$. persimilis female was transferred onto each disc on half the number of leaf discs, while the other leaf discs were left without predators. The water surface within compartments reached slightly above the compartment edge, preventing the predators from leaving the disc. After $12 \mathrm{~h}$ the predator female and her eggs (if any laid) were removed and the discs ready for use in experiments.

\section{NO-CHOICE EXPERIMENT}

In the no-choice experiment we compared the activity and oviposition behavior of predator-naïve and -experienced T. urticae females on discs with and without predatory mite cues. To this end, predator-naïve or -experienced T. urticae females were singly placed on leaf discs, floating on water columns, with or without predator cues, resulting in four treatments. After adding the spider mite female, activity (moving or stationary) and oviposition were recorded every $10 \mathrm{~min}$ in the first $\mathrm{h}$ and every $20 \mathrm{~min}$ during the ensuing $5 \mathrm{~h}$. After $24 \mathrm{~h}$ the activity was recorded once again and the total number of eggs was determined. Each treatment was replicated 29 times, and each leaf disc and each spider mite female were used only once.

\section{CHOICE EXPERIMENT}

In the choice experiment we evaluated the residence and oviposition site preference of predator-naïve and -experienced T. urticae given a choice between two sites with and without predatory mite cues. Each choice unit consisted of two leaf discs-one with and one without predatory mite cues-placed on moist filter paper on 
top of a foam cube $(6 \times 6 \times 5 \mathrm{~cm})$ at a distance of $15 \mathrm{~mm}$. The gap between the leaf discs was filled by a T-shaped wax bridge (Walzer et al., 2006), created by dripping hot wax from a non-fragrant candle onto the filter paper. The position (left or right) of the disc with predatory mite cues was randomly chosen and switched between replicates. The experiment was started by releasing one predator-naïve or -experienced T. urticae female at the bottom end of the T-shaped wax bridge. After release, the female was monitored until reaching one of the two leaf discs (first choice) and then her location, activity and oviposition were recorded every $30 \mathrm{~min}$ for $240 \mathrm{~min}$ in total. Each treatment, predator-naïve and -experienced T. urticae females, was replicated 30 times, and each choice unit and spider mite female was used only once.

\section{STATISTICAL ANALYSES}

SPSS 20 was used for all statistical analyses. In the no-choice experiment, the activity of the females (moving or stationary) was compared between the four treatments over time by generalized estimating equations (GEE; binomial distribution, logit link) with an autocorrelation structure between observations (used as inner subject factor) (Hardin and Hilbe, 2012). To compare the time of the first egg laid and the total oviposition (number of eggs laid within $24 \mathrm{~h}$ ) among the four treatments, we conducted separate univariate analyses of variance (ANOVA). In the choice experiment the position (leaf disc with or without predator cues) and activity (moving, stationary) of predator-naive and -experienced T. urticae over time were compared by GEE (binomial distribution, logit link) with an autocorrelation structure between observations (used as inner subject factor). First choice within each treatment (predator-naïve and -experienced females) was analyzed by two-tailed binomial tests assuming random choice of the two leaf discs. To evaluate the general site preference within each treatment, Wilcoxon-signed-rank tests using the pooled position data of each spider mite individual (leaf disc with or without predator cues) were performed. Paired $t$-tests were applied to determine the oviposition site preference (number of eggs laid on leaf discs with/without predator cues) of naïve and experienced T. urticae.

\section{RESULTS}

\section{NO-CHOICE EXPERIMENT}

Time of the first egg laid was significantly affected by the presence of predator cues and predator experience. Predator-naïve T. urticae laid their first egg later on both types of leaves than experienced ones [ANOVA: $F_{(1,105)}=4.881, P=0.03$ ]. Both naïve and experienced spider mites laid their first egg earlier on leaf discs without predator cues $\left[F_{(1,105)}=5.980, P=0.02\right]$. There was no interaction between experience and predator cues $\left[F_{(1,105)}=0.137, P=0.71\right]$ (Figure 1). Total oviposition of the spider mites was neither affected by predator experience [ANOVA: $F_{(1,112)}=0.055, P=0.82$ ] nor presence of predator cues $\left[F_{(1,112)}=2.313, P=0.13\right]$. However, the significant interaction $\left[F_{(1,112)}=4.434, P=0.04\right]$ indicates that predator-naïve spider mites laid fewer eggs on leaf discs with predator cues, whereas experienced mites laid similar numbers of eggs on both leaf disc types, with and without predator cues (Figure 1). Activity (moving or stationary) of the spider mites was affected by predator-experience (GEE: Wald $\mathrm{x}_{1}^{2}=5.600, P=0.02$ ), presence of predator cues (Wald $\mathrm{x}_{1}^{2}=$ $31.907, P<0.001$ ) and either factor nested in time (Wald $x_{1}^{2}=$ 4.685, $P=0.03$ and Wald $\left.x_{1}^{2}=4.867, P=0.03\right)$. Predator-naïve spider mite females were more active and showed a constant decrease of activity over time while predator-experienced spider mites were overall less active, strongly reducing their activity within the first $40 \mathrm{~min}$ and then remaining on a low activity level for the rest of the experiment (Figure 2). Both predator-naïve and -experienced spider mite females showed a higher activity level and decreased their activity later on leaf discs with than without predator cues.

\section{CHOICE EXPERIMENT}

Both predator-naïve (Wilcoxon signed-rank test: $N=30$, $Z=-2.657, P=0.008$ ) and -experienced spider mite females
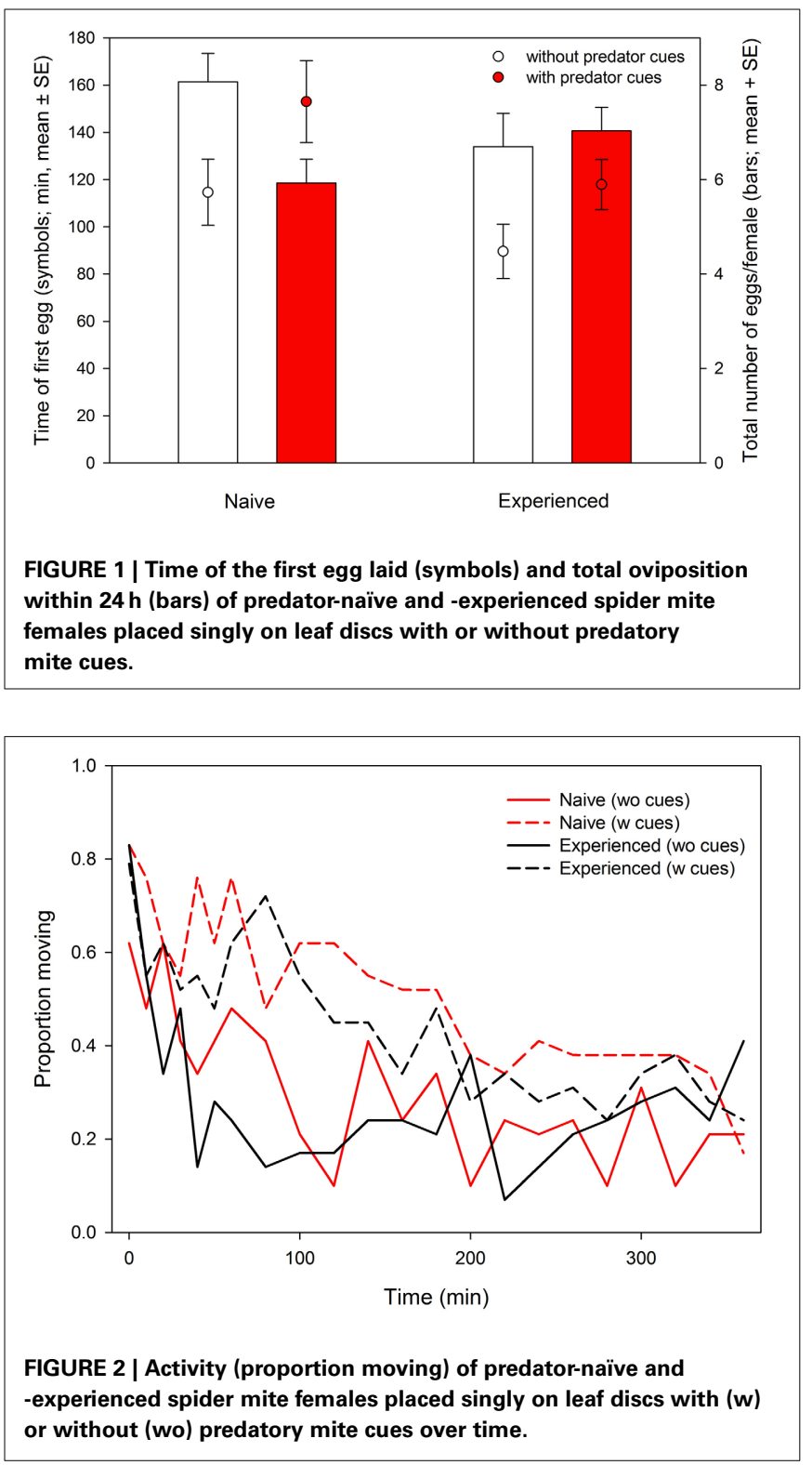
$(N=30, Z=-2.194, P=0.03)$ preferentially resided on leaf discs without predator cues (Figure 3). First choice by the females was completely random (two-tailed binomial tests: $N=30, P=0.86$ for predator-naïve and $N=30, P=1.0$ for predator-experienced mites). Predator experience had no effect on oviposition [ANOVA: $F_{(1,57)}=0.852, P=0.36$ ] but both predator-naïve [paired samples $t$-test: $t_{(29)}=-2.262$, $P=0.03]$ and -experienced $\left[t_{(28)}=-2.013, P=0.05\right]$ spider mite females deposited more eggs on leaf discs without predator cues (Figure 3). Predator experience had no effect on the overall activity level of the spider mites (GEE: Wald $\left.x_{1}^{2}=2.367, P=0.82\right)$ but had an effect when nested in time (Wald $x_{14}^{2}=64.607, P<0.001$ ). Predator-experienced spider mite females reduced their activity strongly during the first $60 \mathrm{~min}$ and then stayed on this level, while predator-naïve spider mites decreased their activity continuously over time (Figure 4).

\section{DISCUSSION}

Our study suggests that previous predator experience modulates the response of two-spotted spider mites, $T$. urticae, to chemosensory predator cues and allows enhanced predation risk management. Predator-experienced spider mites coming from high risk environments responded less fearful to latent predation risk, because not constituting an immediate risk, than spider mites coming from benign environments. While learning by two-spotted spider mites has been shown before in the context of host plant choice (Egas and Sabelis, 2001; Patiño-Ruiz and Schausberger, 2014) our study is the first to show that learning also modulates their anti-predator behaviors.

\section{NO-CHOICE EXPERIMENT}

The first, no-choice experiment confirmed that T. urticae has an innate ability to recognize chemosensory cues left by $P$. persimilis on the leaf surface, which is in accordance with recent related studies by Fernández-Ferrari and Schausberger (2013). Both predator-naïve and -experienced spider mites laid their first egg earlier on leaf discs without than with predator cues. However, experience influenced the time of first oviposition. Predatorexperienced mites laid their first egg earlier than its naïve conspecifics did. Thus, predator experience did not totally offset the delay in first oviposition but attenuated the response of the spider mites to the chemosensory predator cues. Predator-naïve mites laid more eggs on leaf discs without than with predator cues while the total number of eggs laid by experienced mites did not differ between discs with and without predator cues. Both predator-naïve and -experienced spider mites reduced their activity earlier on leaf discs without than with predator cues. However, predator-experienced mites reduced their activity earlier and more strongly than predator-naïve mites did and remained on a low activity level for most of the experiment. Thus, regarding activity both predator-naïve and -experienced spider mites showed qualitatively the same innate response but, similar to oviposition, learning attenuated the response of the spider mites to the predator cues. These results suggest that experience changed information processing and altered the response of the spider mites to the predator cues over time.

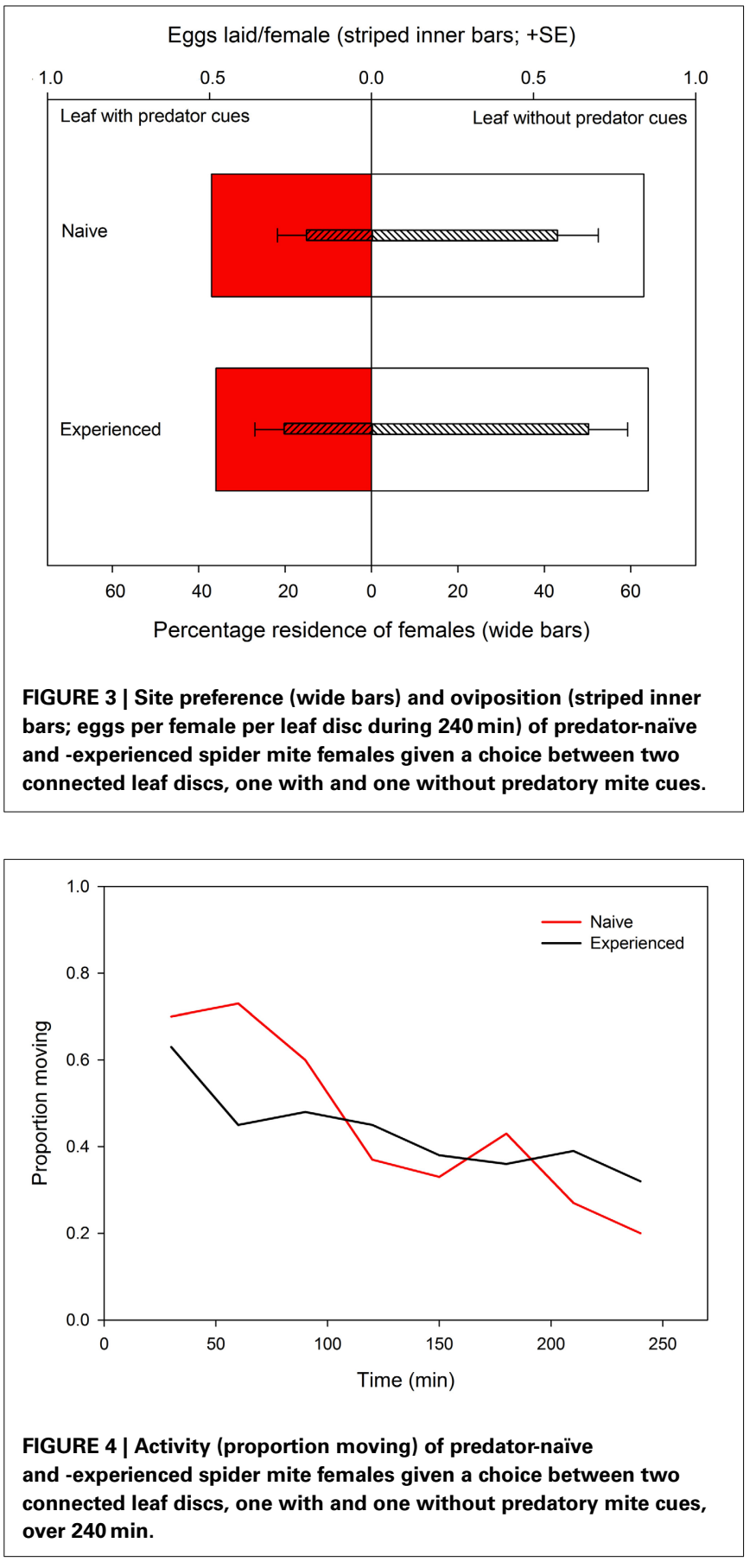

The observed anti-predator strategies of the spider mites are similar to those reported in previous studies (Grostal and Dicke, 1999; Skaloudová et al., 2007; Fernández-Ferrari and Schausberger, 2013) but differ in various details. Moreover, all previous studies concerned with spider mite responses to predators or their cues only investigated the behavior of predatornaïve individuals and are therefore only directly comparable to the behavior of naïve spider mites in our work. Grostal and Dicke (1999) examined the influence of direct and indirect cues of $P$. persimilis on foraging and oviposition decisions 
of T. urticae. They placed single adult females on predatorexposed and -unexposed leaf discs but, after $24 \mathrm{~h}$, did not find changes in oviposition. Their findings are different from our results for predator-naïve $T$. urticae (significant effect of predator cues on oviposition within $24 \mathrm{~h}$ ) but similar to our results for predator-experienced ones (no effect of predator cues on oviposition within $24 \mathrm{~h}$ ). The differences may be due to using different experimental set-ups. We released the spider mites immediately but Grostal and Dicke (1999) only $2 \mathrm{~h}$ after predator removal. In Grostal and Dicke (1999) the chemosensory predator cues may have partly vanished, thus not causing or weakening the response of the spider mites. Like the predatornaïve mites in our study, Skaloudová et al. (2007) observed oviposition shifts in T. urticae when exposed to $P$. persimilis cues and detected that increasing risk correlated with decreasing oviposition. Using a similar set-up to our study, FernándezFerrari and Schausberger (2013) investigated the threat-sensitive response of $T$. urticae females to cues of three predatory mite species posing different risks ( $P$. persimilis, Neoseiulus californicus, and Amblyseius andersoni). They released one randomly selected adult spider mite female either on a blank leaf disc or on a leaf disc harboring traces left by the predator females on the surface or predator traces plus predator eggs. Coincident with our findings for predator-naïve T. urticae, they detected an earlier onset of oviposition and higher total oviposition within $24 \mathrm{~h}$ on blank leaf discs than on leaf discs with predator cues.

Regarding activity, the studies by Oku et al. (2004), Skaloudová et al. (2007) and Fernández-Ferrari and Schausberger (2013) revealed similar results, i.e., higher activity levels in presence of predator cues, as our experiments. Predator avoidance through emigration was shown for T. urticae by Pallini et al. (1999) and the cassava green mite, Mononychellus tanajoa by Magalhães et al. (2002). However, in these two studies the spider mites had the possibility to leave the risky places. In our experimental set-up emigration was impossible because the leaf discs were surrounded by water. The higher activity level may thus reflect attempts to find an exit or a safer place for oviposition. This may also explain why both groups, predator-naïve and -experienced spider mites, showed a higher activity level in presence of predator cues but cannot explain the attenuated response of predator-experienced mites relative to predatornaïve ones. Adjusted risk management (e.g., Jachner, 2001; Epp, 2013), i.e., coming to a relatively safe place after physical exposure to predators, could have been responsible, as for oviposition, for the activity shifts of experienced mites. Proximately, the differing activity levels may also explain the differences in time of the first egg laid. Both naïve and experienced mites laid their first egg earlier on leaf discs without predator cues. Less time spent moving on clean leaf discs allowed spending more time feeding, which, in consequence, may have resulted in an earlier onset of oviposition. Previous predator experience led to earlier oviposition on both leaf disc types as compared to naïve mites. Accordingly, the earlier and stronger decrease in activity of predator-experienced than -naïve mites may have correlated with increased foraging and earlier egg deposition.

\section{CHOICE EXPERIMENT}

The second, choice, experiment revealed that both predatornaïve and-experienced spider mites avoided residing on leaf discs with predator cues. Similarly, both types of spider mites preferred the leaf disc without predator cues for oviposition. First choice of both predator-naïve and-experienced spider mites was completely random, indicating that they perceived the predator cues only at close range (on the leaf disc) by olfaction and/or taste. Activity over time differed between predator-naïve and -experienced T. urticae. Similar to the no-choice experiment, experienced mites reduced their activity earlier than naïve ones did. These results correspond to the findings of previous topically related studies, which similarly showed that herbivorous mites such as T. urticae avoid plants harboring their predators or predator cues (Grostal and Dicke, 1999; Pallini et al., 1999; Magalhães et al., 2002). Like in the no-choice experiment, a possible explanation for the rapid activity decrease of experienced mites may be adjusted risk management (e.g., Jachner, 2001; Epp, 2013).

\section{LEARNED PREDATION RISK MANAGEMENT}

The effects of previous predator experience on spider mite behavior were opposite to the common observation that experience intensifies or strengthens anti-predator responses, because improving the abilities to detect and respond to cues associated with predation risk. Such patterns have been observed in many animals (e.g., Wisenden and Millard, 2001 for flatworms; Murray et al., 2004 for amphibians; de Oliveira Mesquita and Young, 2007 for fishes) incl. predatory mites (Walzer and Schausberger, 2011, 2012). In our experiments, predator-experienced spider mites responded less intensely to chemosensory predator cues and thus acted bolder than predator-naïve ones. Spider mites coming from a high immediate risk environment, characterized by a suite of cues indicating predation risk such as physically present predators, dead conspecifics and chemosensory predator traces, obviously interpreted an environment with predator traces alone (chemosensory cues but no physical predator presence and no predator eggs) as less risky than predator-naïve spider mites coming from a benign, predator-free environment. Jachner (2001) observed an analogous response in predatornaïve and -experienced roach, Rutilus rutilus, and explained the weaker response of experienced fish to alarm cues as adjusted risk assessment or habituation. Similarly, Epp (2013) observed that experienced San Marcos salamander, Eurycea nana, responded less intensely to predator cues than naïve ones did and suggested either habituation or learned irrelevance as underlying mechanisms. Assuming non-associative learning, habituation to predator traces (i.e., a reduced response to a repeated stimulation that is not caused by fatigue or sensory adaption; Rankin et al., 2009) or related phenomena may apply to the responses of predator-experienced T. urticae in our experiments as well. Assuming some form of associative learning (learning to associate the stimulus pair - physical predator presence and chemosensory traces - with high predation risk), the experienced spider mites could have later interpreted an environment where one of the two stimuli (physical predator presence) was absent as a relatively low risk, whereas the naïve ones could not make such risk adjustment. Under an operant conditioning paradigm it could be that 
the response to chemosensory predator traces was first negatively reinforced, because followed by the reward of less likely encountering a predator, and then extinguished, because of a missing consequence, leading to a reduced response to predator traces. Ultimately, we consider the behavior of the predator-experienced spider mites as adaptive learned predation risk management. Only experience allowed the spider mites to interpret chemosensory predator traces alone as relatively harmless because they had learned that high risk is represented by predator traces plus physical predator presence. Accordingly, predator-experienced spider mites compensated the fitness loss, which they suffered in the high immediate risk environment, by bolder anti-predator behavior in the low risk environment. In comparison to experienced spider mites, naïve spider mites overreacted to the exclusive presence of chemosensory predator cues, because not representing immediate risk.

\section{CONCLUSIONS}

Altogether and in line with previous studies we observed innate anti-predator behavior of the spider mite T. urticae when exposed to chemosensory traces left by its predator $P$. persimilis on leaves. The spider mites responded to predation risk with a delayed onset of oviposition, decreased oviposition, and increased activity. A novel finding of our study is that learning allowed the spider mites to modify their innate anti-predator behaviors. Learning did not intensify or strengthen but attenuate the spider mite response to the predator cues. Pinpointing the underlying learning mechanism requires further investigations. Based on the fact that every anti-predator behavior has fitness costs (Lima, 1998) we argue that the attenuated response of the spider mites to chemosensory predator cues alone indicates adaptive learned predation risk management.

\section{AUTHOR CONTRIBUTIONS}

Peter Schausberger conceived the study idea; Thomas Hackl and Peter Schausberger designed the experiments; Thomas Hackl performed the experiments; Thomas Hackl and Peter Schausberger analyzed the data; Thomas Hackl and Peter Schausberger wrote the manuscript.

\section{ACKNOWLEDGMENTS}

We thank A. Walzer, M. J. Gratzer, M. Seiter, D. Çekin and I. C. Christiansen for comments on an earlier version of this manuscript.

\section{REFERENCES}

Blackwood, J. S., Schausberger, P., and Croft, B. A. (2001). Prey stage preference in generalist and specialist phytoseiid mites (Acari: Phytoseiidae) when offered Tetranychus urticae (Acari: Tetranychidae) eggs and larvae. Environ. Entomol. 30, 1103-1111. doi: 10.1603/0046-225X-30.6.1103

Bolland, H. R., Gutierrez, J., and Flechtmann, C. H. W. (1998). World Catalogue of the Spider Mite Family (Acari, Tetranychidae). Leiden: Brill.

Chivers, D. P., and Smith, R. J. F. (1998). Chemical alarm signalling in aquatic predator prey systems: a review and prospectus. Ecoscience 5, 338-352.

de Oliveira Mesquita, F., and Young, R. J. (2007). The behavioural responses of nile tilapia (Oreochromis niloticus) to anti-predator training. Appl. Anim. Behav. Sci. 106, 144-154. doi: 10.1016/j.applanim.2006.06.013

Egas, M., and Sabelis, M. W. (2001). Adaptive learning of host preference in a herbivorous arthropod. Ecol. Lett. 4, 190-195. doi: 10.1046/j.14610248.2001.00219.x
Epp, K. J. (2013). Threat sensitivity in the San Marcos salamander: effects of predator diet and prey experience. Behaviour 150, 617-634. doi: 10.1163/1568539X00003073

Fernández-Ferrari, M. C., and Schausberger, P. (2013). From repulsion to attraction: species- and spatial context-dependent threat sensitive response of the spider mite Tetranychus urticae to predatory mite cues. Naturwissenschaften 100, 541-549. doi: 10.1007/s00114-013-1050-5

Ferrari, M. C. O., and Chivers, D. P. (2006). Learning threat-sensitive predator avoidance: how do fathead minnows incorporate conflicting information? Anim. Behav. 71, 19-26. doi: 10.1016/j.anbehav.2005.02.016

Ferrari, M. C. O., Messier, F., and Chivers, D. P. (2006). The nose knows: minnows determine predator proximity and density through detection of predator odours. Anim. Behav. 72, 927-932. doi: 10.1016/j.anbehav.2006.03.001

Gallie, J. A., Mumme, R. L., and Wissinger, S. A. (2001). Experience has no effect on the development of chemosensory recognition of predators by tadpoles of the American toad, Bufo americanus. Herpetologica 57, 376-383.

Grostal, P., and Dicke, M. (1999). Direct and indirect cues of predation risk influence behavior and reproduction of prey: a case for acarine interactions. Behav Ecol. 10, 422-427. doi: 10.1093/beheco/10.4.422

Grostal, P., and Dicke, M. (2000). Recognising one's enemies: a functional approach to risk assessment by prey. Behav. Ecol. Sociobiol. 47, 258-264. doi: $10.1007 / \mathrm{s} 002650050663$

Hardin, J. W., and Hilbe, J. M. (2012). Generalized Estimating Equations, 2nd Edn., Boca Raton, FL: Chapman and Hall/CRC.

Helfman, G. S. (1989). Threat-sensitive predator avoidance in damselfishtrumpetfish interactions. Behav. Ecol. Sociobiol. 24, 47-58. doi: 10.1007/BF00300117

Jachner, A. (2001). Anti-predator behaviour of naïve compared with experienced juvenile roach. J. Fish Biol. 59, 1313-1322. doi: 10.1111/j.10958649.2001.tb00194.x

Kats, L. B., and Dill, L. M. (1998). The scent of death: chemosensory assessment of predation risk by prey animals. Ecoscience $5,361-394$.

Kelley, J. L., and Magurran, A. E. (2003). Learned predator recognition and antipredator responses in fishes. Fish Fish. 4, 216-226. doi: 10.1046/j.14672979.2003.00126.x

Lima, S. L. (1998). Nonlethal effects in the ecology of predator-prey interactions. Bioscience 48, 25-34. doi: 10.2307/1313225

Lima, S. L., and Dill, L. M. (1990). Behavioral decisions made under the risk of predation: a review and prospectus. Can. J. Zool. 98, 619-659. doi: 10.1139/z 90-092

Magalhães, S., Janssen, A., Hanna, R., and Sabelis, M. W. (2002). Flexible antipredator behaviour in herbivorous mites through vertical migration in a plant. Oecologia 132, 143-149. doi: 10.1007/s00442-002-0950-4

Maloney, R. F., and McLean, I. G. (1995). Historical and experimental learned predator recognition in free-living New Zealand robins. Anim. Behav. 50, 1193-1201. doi: 10.1016/0003-3472(95)80036-0

Mathis, A., Chivers, D. P., and Smith, R. J. F. (1996). Cultural transmission of predator recognition in fishes: intraspecific and interspecific learning. Anim. Behav. 51, 185-201. doi: 10.1006/anbe.1996.0016

Murray, D. L., Roth, J. D., and Wirsing, A. J. (2004). Predation risk avoidance by terrestrial amphibians: the role of prey experience and vulnerability to native and exotic predators. Ethology 110, 635-647. doi: 10.1111/j.1439-0310.2004.01004.x

Oku, K., Yano, S., and Takafuji, A. (2004). Nonlethal indirect effects of a native predatory mite, Amblyseius womersleyi Schicha (Acari: Phytoseiidae), on the phytophagous mite Tetranychus kanzawai Kishida (Acari: Tetranychidae). J. Ethol. 22, 109-112. doi: 10.1007/s10164-003-0102-2

Pallini, A., Janssen, A., and Sabelis, M. W. (1999). Spider mites avoid plants with predators. Exp. Appl. Acarol. 23, 803-815. doi: 10.1023/A:1006266232714

Patiño-Ruiz, J. D., and Schausberger, P. (2014). Spider mites adaptively learn recognizing mycorrhiza-induced changes in host plant volatiles. Exp. Appl. Acarol. doi: 10.1007/s10493-014-9845-4. [Epub ahead of print].

Rankin, C. H., Abrams, T., Barry, R., Bhatnagar, S., Clayton, D., Colombo, J., et al. (2009). Habituation revisited: an updated and revised description of the behavioral characteristics of habituation. Neurobiol. Learn. Mem. 92, 135-138. doi: 10.1016/j.nlm.2008.09.012

Sih, A. (1982). Foraging strategies and the avoidance of predation by an aquatic insect, Notonecta hofmanni. Ecology 63, 786-796. doi: 10.2307/1936799

Skaloudová, B., Zemek, R., and Křivan, V. (2007). The effect of predation risk on an acarine system. Anim. Behav. 74, 813-821. doi: 10.1016/j.anbehav.2007.02.005 
Turner, A. M., Turner, S. E., and Lappi, H. M. (2006). Learning, memory and predator avoidance by freshwater snails: effects of experience on predator recognition and defensive strategy. Anim. Behav. 72, 1443-1450. doi: 10.1016/j.anbehav.2006.05.010

Walzer, A., Paulus, H. F., and Schausberger, P. (2006). Oviposition behavior of interacting predatory mites: response to the presence of con- and heterospecific eggs. J. Insect Behav. 19, 305-320. doi: 10.1007/s10905-006-9025-4

Walzer, A., and Schausberger, P. (2011). Threat-sensitive anti-intraguild predation behavior: maternal strategies to reduce offspring predation risk in mites. Anim. Behav. 81, 177-184. doi: 10.1016/j.anbehav.2010.09.031

Walzer, A., and Schausberger, P. (2012). Integration of multiple intraguild predator cues for oviposition decisions by a predatory mite. Anim. Behav. 84, 1411-1417. doi: 10.1016/j.anbehav.2012.09.006

Wisenden, B. D., and Millard, M. (2001). Aquatic flatworms use chemical cues from injured conspecifics to assess predation risk and to associate risk with novel cues. Anim. Behav. 62, 761-766. doi: 10.1006/anbe.2001.1797
Conflict of Interest Statement: The authors declare that the research was conducted in the absence of any commercial or financial relationships that could be construed as a potential conflict of interest.

Received: 04 June 2014; accepted: 01 September 2014; published online: 16 September 2014.

Citation: Hackl T and Schausberger P (2014) Learned predation risk management by spider mites. Front. Ecol. Evol. 2:58. doi: 10.3389/fevo.2014.00058

This article was submitted to Behavioral and Evolutionary Ecology, a section of the journal Frontiers in Ecology and Evolution.

Copyright (C) 2014 Hackl and Schausberger. This is an open-access article distributed under the terms of the Creative Commons Attribution License (CC BY). The use, distribution or reproduction in other forums is permitted, provided the original author(s) or licensor are credited and that the original publication in this journal is cited, in accordance with accepted academic practice. No use, distribution or reproduction is permitted which does not comply with these terms. 